Jurnal Farmasi Higea, Vol. 11, No. 2, 2019

\title{
Rasionalitas Penggunaan Obat Diabetes Mellitus Tipe 2 komplikasi Nefropati di Rumah Sakit Umum Pusat dr. M.Djamil Padang
}

\author{
Widya Kardela $^{I^{*}}$, Rahmad Abdillah ${ }^{2}$, Garmi Handicka ${ }^{1}$ \\ ${ }^{1)}$ Sekolah Tinggi Ilmu Farmasi (STIFARM) Padang \\ ${ }^{2}$ Fakultas Farmasi, Universitas Andalas Padang \\ *E-mail: kardelawidya@stifarm-padang.ac.id
}

\begin{abstract}
Abstrak
Diabetes merupakan sindrom yang disebabkan oleh kekurangan insulin secara relative dan atau absolut. Diabetes mellitus tipe 2 lebih disebabkan oleh kerusakan sekresi insulin dan resistensi insulin daripada defisiensi insulin. Diabetes mellitus komplikasi nefropati dapat memicu kegagalan fungsi ginjal. Pengobatan yang rasional mengharuskan pasien diabetes mellitus (DM) tipe 2 komplikasi nefropati (ND) untuk mendapatkan pengobatan yang sesuai dengan keadaan dan kondisi pasien yang mana dapat dipantau dengan indikator $4 \mathrm{~T}+1 \mathrm{~W}$. Penelitian ini bertujuan mengevaluasi kerasionalan penggunaan obat antidiabetes pada pasien DM tipe 2 komplikasi ND rawat inap RSUP DR.M.Djamil padang. Studi prospektif dengan metode cross sectional menggunakan data rekam medis dan wawancara. Hasil penelitian menunjukan bahwa dari 32 pasien, yang memenuhi kriteria inklusi hanya 20 pasien (62\%). Pembagian pasien berdasarkan jenis kelamin mendapati 13 pasien $(56 \%)$ pasien wanita lebih banyak dibandingkan dengan pasien pria hanya 6 pasien $(44 \%)$ dan rentang umur yang paling banyak menderita penyakit tersebut adalah lansia akhir dengan 8 pasien $(40 \%)$ serta tingkat pendidikan pasien yang banyak adalah sekolah menengah atas (SMA) yaitu 12 pasien (60\%). Hasil evaluasi penggunaan obat antidiabetes dan antihipertensi pada rumah sakit tersebut mendapati $100 \%$ tepat indikasi, tepat obat, tepat pasien dan telah waspada terhadap efek samping. Sedangkan kajian ketepatan dosis terhadap obat antidiabetes dan antihipertensi sebesar $57 \%$ dan $90 \%$. Pada penelitian ini ditemukan adanya ketidaktepatan regimen dosis.
\end{abstract}

Kata kunci: Diabetes Mellitus; Diabetes Nefropati; Rasionalitas Penggunaan Obat

\begin{abstract}
Diabetes is a syndrome that is caused by a relative or an absolute lack of insulin. Impaired insulin secretion and resistance to the action of insulin, rather than an absolute insulin deficiency, characterize patient with type 2 diabetes. Diabetic nephropathy is a leading cause of end stage renal disease. Drug utilization studies could promote rational drug use. The project aimed to assess and evaluate the rationality of drug use in patients with type 2 Diabetes Mellitus complication of Diabetic Nephrophaty inpatient care at dr. M.Djamil Hospital Centre Padang. A prospective, crossectional method was conducted in this non experimental research. The demographic, disease and treatment data of patients with diabetic nephropathy were collected for a period of three months and analysed. The appropriateness of antidiabetic usage based on criterion Ministry oh Health, such as the appropriateness of indication, the appropriateness of patient, the appropriateness of regiment, the appropriateness of drug and caution of side effect. The results showed that antidiabetic and antihypertensive usage on that hospital were $100 \%$ appropriate in term of indication, patient, drug and caution of side effect. While evaluation to appropriateness of antidiabetic and antihypertensive drug regiment were 57\% and 90\% respectively. This study find anappropriate in drug regiment.
\end{abstract}

Keywords: Diabetes Mellitus Type 2; Diabetic nephropathy; rational drug use 


\section{PENDAHULUAN}

Diabetes Mellitus (DM) adalah
suatu sindrom hiperglikemia kronik
disebabkan oleh kekurangan insulin dan
atau resistensi insulin. Hal ini mengakibatkan lebih dari 120 juta dan diperkirakan akan lebih dari 220 juta orang terkena penyakit DM diseluruh dunia pada tahun 2020 (Kumar \& Clark, 2005). Penyakit DM yang tidak terkontrol dengan baik dapat menimbulkan komplikasi akut dan kronis, salah satu komplikasi penyakit DM adalah terbentuknya Nefropati (Departemen Kesehatan Republik Indonesia, 2005). Nefropati Diabetik (ND) didefinisikan sebagai sindrom klinis pada penderita DM yang ditandai dengan albuminuria menetap yaitu > $300 \mathrm{mg} / 24$ jam pada minimal dua kali pemeriksaan dalam kurun waktu 3 sampai 6 bulan. ND merupakan penyebab utama terjadinya gagal ginjal (Hendromartono, 2009). Angka prevalensi global dari ND adalah 13,4\% dan hampir 60\% penderita DM di Asia menderita ND. Sedangkan di Indonesia perawatan penyakit ND atau gangguan ginjal merupakan rangking ke 2 pembayaran terbesar dari BPJS. (Kementerian Kesehatan Republik indonesia (INFODATIN), 2017; Mogensen CE, 2000). Penyakit DM dan ND adalah penyakit tidak menular yang tidak dapat disembuhkan tetapi hanya bisa dikontrol maka pengobatan penyakit DM dan ND memiliki jangka waktu penggunaan obat yang panjang dan hal ini dapat menyebabkan ketidakrasionalan dalam terapi dan penggunaan obat. Penggunaan obat dikatakan obat yang rasional apabila pasien menerima obat yang sesuai dangan kebutuhannya, baik dalam jangka waktu yang sesuai dan dengan harga yang murah untuk pasien dan masyarakat (World Health Organization, 1985).

Pemberian dan penyerahan obat pada pasien dengan penyakit degeneratif harus diberikan pemantauan agar tidak terjadi reaksi yang tidak diinginkan. Reaksi yang tidak diinginkan dapat berupa timbulnya ketidaktepatan indikasi obat dan hal tersebut dibuktikan oleh beberapa penelitian pada kurun waktu 1 dekade yang lalu seperti Hongdianto et al (2014), Almasdy et al (2015), dan Robianto et al (2017). Penelitian lain yang dilakukan oleh Swastika (2007) menyimpulkan hasil pengobatan DM dengan komplikasi ND terdapat kesalahan berupa masalah terkait obat yang mengakibatkan $32,3 \%$ pasien pulang dalam keadaan buruk. Dengan demikian masih dibutuhkan evaluasi rasionalitas penggunaan obat.

\section{METODE PENELITIAN}

Jenis penelitian adalah non eksperimental dengan rancangan deskriptif dan menggunakan metode cross sectional serta pengambilan data secara Prospektif. Data diperoleh dari rekam medis dan tinjauan langsung pada pasien BPJS rawat inap DM tipe 2 komplikasi ND di RSUP DR.M.Djamil Padang.

\section{Penetapan Populasi dan Sampel}

1. Populasi

Populasi penelitian ini adalah semua pasien dengan penyakit DM tipe 2 di RSUP DR.M.Djamil Padang pada periode November 2018 dan Januari 2019.

2. Sampel

Sampel penelitian ini adalah seluruh pasien BPJS rawat inap dengan diagnosa DM tipe 2 komplikasi ND pada periode Noveber sampai Januari tahun 2018-2019 yang memenuhi kriteria inklusi. Pangambilan sampel dilakukan dengan metode purposive sampling. Apabila sampel pada bulan November sampai dengan Januari sangat besar, maka pengambilan sampel 
dibatasi maksimal 183 sampel yang didapatkan dari rumus penetapan besaran sampel Notoadmodjo 2005.

Kriteria inklusi :

1. Pasien DM tipe 2 komplikasi ND dengan umur dewasa akhir hingga manula (36 s/d $\geq 65$ tahun).

2. Pasien yang dirawat pada poli penyakit dalam.

3. Pasien yang dirawat pada bulan November 2018 sampai dengan bulan Januari 2019.

Kriteria ekslusi :

1. Pasien umum.

2. Pasien hamil.

3. Pasien yang dirawat pada ruang inap lain.

Kriteria drop out

1. Pasien yang meninggal dunia.

2. Pasien keluar paksa.

Data yang diperoleh akan analisa dan dievaluasi dengan indikator $(4 \mathrm{~T}+1 \mathrm{~W})$ yaitu : tepat indikasi, tepat obat, tepat dosis, tepat pasien dan waspada efek samping yang telah ditetapkan oleh Kementerian Kesehatan Republik Indonesia. Data yang diperoleh dianalisa dan dilakukan perhitungan manual dengan bantuan rumus. Kemudian data ditampilkan dalam bentuk tabel dan grafik.

\section{Hasil dan Pembahasan}

Karakteristik sosiodemografi pasien DM tipe 2 Nefropati adalah pasien wanita sebanyak 13 orang $(65 \%)$ dan data pasien pria sebanyak 7 orang (35\%). pasien lansia akhir (56-65 tahun) sebanyak 8 pasien (40\%), manula sebanyak 6 pasien (35\%), lansia awal sebanyak 5 pasien (25\%) dan dewasa akhir 1 pasien (5\%).
Berdasarkan tingkat pendidikan pasien, didapatkan data sekolah menengah atas (SMA) sebanyak 12 pasien $(60 \%)$, serjana sebanyak 6 pasien $(30 \%)$ dan sekolah menengah pertama (SMP) sebanyak 2 pasien (10\%).

Analisa kerasionalan penggunaan obat antidiabetes

Kerasionalan dari penggunaan obat antidiabetes pada pasien DM tipe 2 komplikasi ND dapat dilihat pada Gambar 1. Berdasarkan obat-obatan yang digunakan oleh 14 pasien diperoleh sebanyak 14 pasien (100\%) tepat obat. sebanyak 8 pasien $(57 \%)$ tepat dosis dan 6 pasien $(43 \%)$ tidak tepat dosis. sebanyak 14 pasien $(100 \%)$ tepat pasien. sebanyak 14 pasien $(100 \%)$ tepat indikasi obat. obat yang diserahkan pada pasien sesuai dengan keadaan klinis pasien. sebanyak 14 pasien $(100 \%)$ waspada efek samping. Obat yang digunaka tidak terdapat efek samping yang membahayakan dan merugikan dari pasien.

\section{Analisa kerasionalan penggunaan obat non antidiabetes atau antihipertensi}

Kerasionalan dari penggunaan obat non antidiabetes atau antihipertensi pada pasien DM tipe 2 komplikasi ND dapat dilihat pada Gambar 2. Berdasarkan obat-obatan yang digunakan oleh 10 pasien diperoleh sebanyak 10 pasien (100\%) tepat obat. sebanyak 9 pasien (90\%) tepat dosis dan 1 pasien $(10 \%)$ tidak tepat dosis. sebanyak 10 pasien $(100 \%)$ tepat pasien. sebanyak 10 pasien $(100 \%)$ tepat indikasi obat. obat yang diserahkan pada pasien sesuai dengan keadaan klinis pasien. sebanyak 10 pasien (100\%) waspada efek samping. 


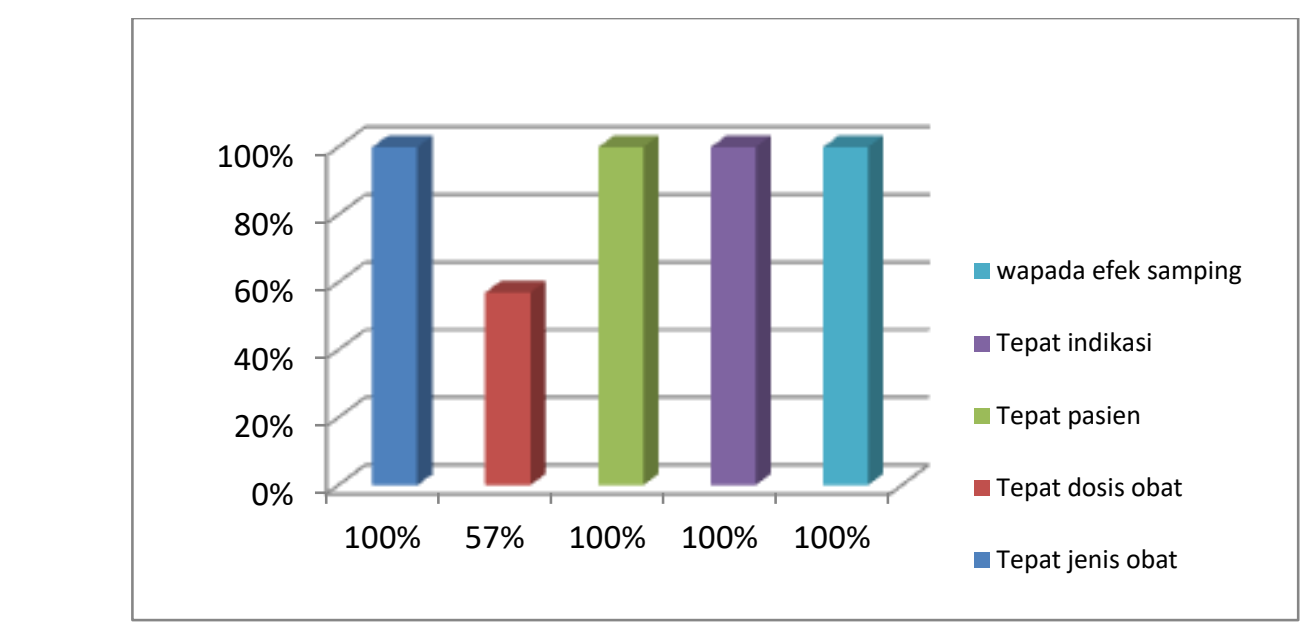

\section{Gambar 1. Grafik analisa kerasionalan obat antidiabetes pada pasien DM tipe 2 komplikasi ND}

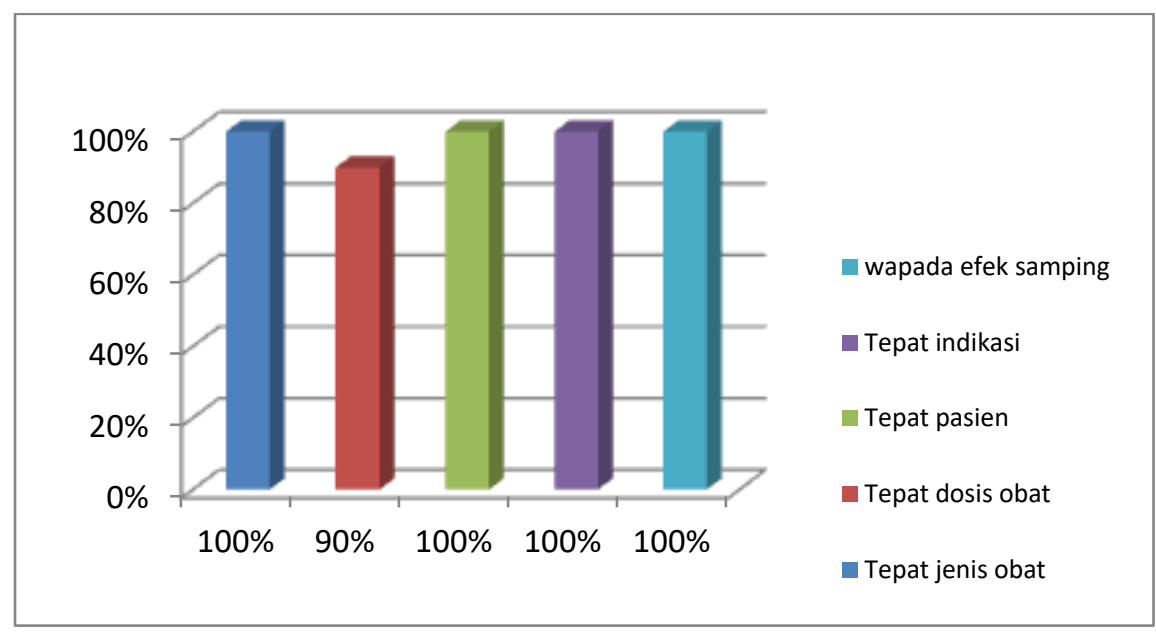

\section{Gambar 7. Grafik Analisa kerasionalan obat non antidiabetes atau obat Antihipertensi pada pasien DM tipe 2 Komplikasi ND}

Berdasarkan data yang diperoleh dari pasien DM tipe 2 komplikas ND mendapati lebih banyak terjadi pada pasien wanita dengan 13 pasien (65\%) dibandingkan pada pasien pria sebanyak 7 pasien (35\%). Pasien pada RSUP DR.M.Djamil padang didapatkan yaitu wanita memiliki resiko lebih besar terkena DM tipe 2 komplikasi ND dibandingkan laki-laki, hal tersebut sesuai penelitian yang dilakukan oleh Almasdy et al (2015) dimana pasien DM tipe 2 rawat inap RSUP DR.M.Djamil Padang tahun 2015 paling banyak adalah pasien wanita hal tersebut disebabkan wanita memiliki peluang peningkatan indeks masa tubuh yang lebih besar, sindrom siklus bulanan (premenstrual syndrome), pasca menopose yang membuat distribusi lemak tubuh menjadi mudah terakumulasi (Hongdianto et al., 2014).

Berdasarkan usia pasien didapatkan pasien dengan usia lansia akhir (56-65 tahun) adalah usia yang paling tinggi resiko terkena DM tipe 2 komplikasi ND yaitu sebanyak 8 orang pasien $(40 \%)$ dibandingkan dengan usia dewasa akhir (36-45 tahun) sebanyak 1 pasien (5\%), usia lansia awal (46- 55 tahun) sebanyak 5 pasien $(25 \%)$ dan manula ( $\geq 65$ tahun) 
sebanyak 6 pasien (30\%). Terlihat dari data yang didapatkan bahwa penderita DM tipe 2 mulai rentan dan sering terjadi pada usia lansia akhir (56-65 tahun) yaitu sebanyak 8 pasien (40\%). Berdasarkan data yang diperoleh mendapati hasil yang sama dengan penelitian yang dilakukan Almasdy et al (2015) dan Robyanto et al (2017) dimana pasien yang paling sering menderita DM tipe 2 adalah pasien dengan umur $\geq 54$ tahun atau usia lansia akhir. Hal ini mengkonfirmasi informasi dari literatur yang menyatakan DM tipe 2 pada umumnya diderita oleh pasien usia diatas 45 tahun dan gula darah yang tidak terkontrol akan cenderung menimbulkan komplikasi akut dan kronis, salah satu komplikasi yang timbul adalah ND. Umur memiliki keterkaitan erat dengan kenaikan kadar gula darah sehingga semakin meningkat umur maka resiko terkena DM tipe 2 dan komplikasinya semakin besar. Bertambahnya usia, maka keadaan tubuh seseorang akan mengalami penurunan fungsi organ-organ dalam absopsi, distribusi, metabolisme dan ekskresi (Departemen Kesehatan Kesehatan Republik Indonesia 2005 ; Hakim, 2012).

Berdasarkan tingkatan pendidikan pasien maka dapat dibagi menjadi sekolah dasar (SD), sekolah menengah pertama (SMP/ yang setara), sekolah menengah atas (SMA/ yang setara) dan serjana. Berdasarkan hasil penelitian mendapati Kesimpulan

Berdasarkan penggunaan obat antidiabetes pada pasien DM tipe 2 komplikasi ND rawat inap di RSUP DR.M.Djamil Padang periode November 2018 sampai dengan Januari 2019 terdapat ketidakrasionalan penggunaan obat antidiabetes dan non antidiabetes. sekolah menengah atas (SMA/ yang setara) adalah tingkatan pendidikan terakhir yang paling dominan yaitu sebanyak 12 orang pasien (60\%) dibandingkan dengan sekolah menengah pertama (SMP) sebanyak 2 orang pasien $(10 \%)$, dan sarjana sebanyak 6 orang pasien $(30 \%)$.

Penelitian yang dilakukan oleh Putri (2015) mendapati bahwa pasien dengan latar belakang pendidikan yang rendah mempunyai resiko mengalami komplikasi ND lebih besar dibandingkan dengan pasien DM tipe 2 yang berlatar belakang pendidikan tinggi. Menurut Departemen Kesehatan Republik Indonesia (2005) Sehingga dilakukan atau memberikan sosialisasi dan penyuluhan berkaitan dengan penyakit DM tipe 2 untuk meningkatkan pengetahuan dan pemahaman pasien seputar penanganan penyakit DM tipe 2 (Departemen Kesehatan Republik Indonesia, 2005).

Obat antidiabetes yang digunakan pasien akan dikelompokan berdasarkan rute pemberiannya. Obat yang paling banyak digunakan adalah obat dengan rute injeksi atau terapi insulin dimana hanya 2 jenis obat injeksi insulin yang diberikan pada pasien dan 1 jenis obat antidiabetes oral . Hal tersebut dikarenakan tidak semua obat antidiabetes yang bisa diberikan pada pasien DM tipe 2 komplikasi.

\section{Daftar Pustaka.}

Almasdy, D., Sari, D. P., Suhatri, Darwin, D., \& Kurniasih, N. (2015). Evaluasi Penggunaan Obat Antidiabetik Pada Pasien Diabetes Mellitus Tipe 2 di Suatu Rumah Sakit Pemerintahan Kota padang Sumatra Barat, Jurnal Sains Farmasi dan Klinis, 2(1), 104-1-110.

Departemen Kesehatan Republik Indonesia. (2005). Pharmaceutical Care Untuk Penyakit Diabetes Mellitus. Jakarta: Kementerian Kesehatan Republik Indonesia. 
Divisions Of Nephrology, Hypertension And General Internal Medicine. (2011). Chronic Kidney Disease (CKD). California: Divisions of Nephrology, Hypertension And General Internal Medicine.

Hakim, L. (2012). Farmakokinetik Klinik. Yogyakarta: Bursa ilmu.

Hongdianto, A., Yamlean, P.V.Y., \& Supriati, H.S. (2014). Evaluasi Kerasionalan Pengobatan Diabetes Mellitus Tipe 2 pada Pasien Rawat Inap di RSUP.Dr.R.D.Kandou Manado Tahun 2013, Jurnal Ilmiah Farmasi, 3(3), 7985.

Kementerian Kesehatan Republik Indonesia. (2017). INFODATIN Pusat Data Dan Informasi Kementerian Kesehatan RI. Jakarta Selatan: Kementerian Kesehatan Republik Indonesia.

Kumar, P. \& Clark, M. (2005). Clinical Medicine ( $6^{\mathrm{rd}}$ ed). Washington D.C United State of America: Elsevier's Health Sciences Rigths Publishers.
Mogensen, CE. (2000). The Kidney and Hypertension in Diabetes Mellitus (5 ${ }^{\text {rd }}$ ed). Boston Kluwer.

Putri, R. I. (2015). Faktor Determinan Nefropati Diabetik Pada Penderita Diabetes Mellitus Di RSUP DR.M.Soewandhie Surabaya, Jurnal Berkala Epidemiologi, 3(1), 109-121.

Robyanto, Afifah, H., \& Untari, E. K. (2017). Pola Peresepan dan Rasionalitas Pengobatan Pasien Diabetes Mellitus Tipe 2 di RSUP Sultan Syarif Mohamad Alkadrie Pontianak, Social Clinical Pharmacy Indonesia Journal, 1(2), 3-7.

Swastika, M.R.D. (2007). Evaluasi Pengobataan Pada Kasus Diabetes Mellitus Dengan Komplikasi Nefropati Diabetik Di Instalasi Rawat Inap Rumah Sakit Bethesda Yogyakarta Periode Tahun 2005. (Skripsi). Yogyakarta: Universitas Sanata Dharma.

World Health Organization (WHO). (1985). The Rational Use of Drugs. England: Word Health Organization. 